\title{
Acute Stroke Imaging Part I: Fundamentals
}

\author{
K. Butcher, D. Emery
}

\begin{abstract}
Neuroimaging is essential to stroke diagnosis and management. To date, the non-contrast CT has served as our main diagnostic tool. Although brain parenchymal changes visible on CT do provide valuable prognostic information, they provide limited insight into the potential for tissue salvage in response to reperfusion therapy, such as thrombolysis. Newer advanced CT and MRI based imaging techniques have increased the detection sensitivity for hyperacute and chronic parenchymal changes, including ischemia and hemorrhage, permit visualization of blood vessels and cerebral blood flow. This review outlines the basic principles underlying acquisition and interpretation of these newer imaging modalities in the setting of acute stroke. The utility of advanced brain parenchymal and blood flow imaging in the context of acute stroke patient management is also discussed. Part II in this series is a discussion of how these techniques can be used to rationally select appropriate patients for thrombolysis based on pathophysiological data.
\end{abstract}

RÉSUMÉ: Imagerie de l'accident vasculaire cérébral aigu, première partie : notions fondamentales. La neuroimagerie est essentielle au diagnostic et à la prise en charge de l'accident vasculaire cérébral. À ce jour, la tomodensitométrie sans contraste constitue le principal outil diagnostique. Bien que les changements du parenchyme cérébral visibles à la tomodensitométrie fournissent une information précieuse sur le pronostic, ils offrent peu d'informations sur la possibilité de préserver des tissus potentiellement viables en réponse aux traitements de reperfusion comme la thrombolyse. L'imagerie basée sur les techniques nouvelles plus avancées de tomodensitométrie et de résonance magnétique ont augmenté la sensibilité de détection des changements parenchymateux hyperaigus et chroniques, dont l'ischémie et l'hémorragie, et permettent la visualisation des vaisseaux sanguins et du flot sanguin cérébral. Cette revue décrit les principes de base sous-jacents à l'acquisition et à l'interprétation de ces nouvelles modalités d'imagerie dans le contexte de l'accident vasculaire cérébral aigu. L'utilité de l'imagerie spécialisée du parenchyme et du flot sanguin cérébral dans le contexte de la prise en charge de l'accident vasculaire cérébral est également abordée. La deuxième partie de cette série discute de l'utilisation de ces techniques pour sélectionner de façon appropriée les patients pour la thrombolyse en se basant sur des données physiopathologiques.

Can. J. Neurol. Sci. 2010; 37: 4-16

Neuroimaging is essential and integral to stroke diagnosis and management. At a minimum parenchymal imaging is required to differentiate hemorrhagic from ischemic stroke. This can be accomplished with the current standard of care, a non-contrast computed tomography (NCCT) scan. It is possible to define ischemic changes with a higher degree of sensitivity using MRI. In addition, advances in both CT and MRI technology now make it possible to routinely image blood vessels as well as tissue blood flow. Although these investigations do increase the total imaging time, they also are tremendously useful in the acute treatment setting. One impediment to more routine use of these imaging modalities is a lack of clinical confidence in rapidly and accurately interpreting the results of investigation beyond NCCT.

This article reviews the basic principles of stroke image acquisition, interpretation and the clinical context in which they can be applied. In Part II of this series, the evidence for imaging markers of the ischemic penumbra is reviewed. The existence of the penumbra, defined as tissue that is dysfunctional secondary to decreased blood flow but also structurally intact and therefore amenable to salvage, is critical to the success of any acute stroke therapy. ${ }^{1}$ Currently, the existence of the penumbra in most patients is inferred from the results of brain parenchyma studies and the clinical status of the patient, but not actually imaged.

From the Division of Neurology (KB), Department of Diagnostic Imaging (DE), University of Alberta, Edmonton, Alberta, Canada.

Received June 22, 2009. Final Revisions Submitted August 17, 2009. Correspondence to: Ken Butcher, Division of Neurology, 2E3 WMC Health Sciences Centre, University of Alberta, 8440 112th St., Edmonton, Alberta, T6G 2B7, Canada. 


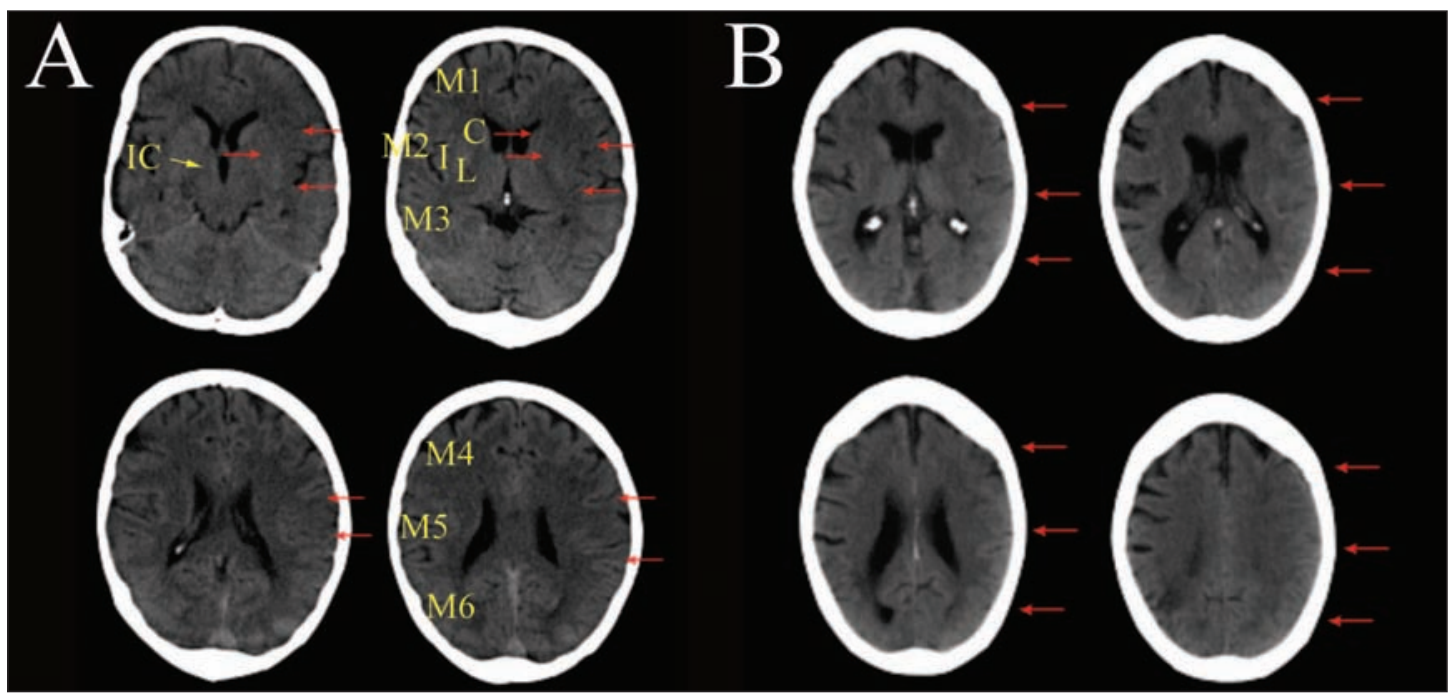

Figure 1: Examples of Early Ischemic Changes. The patient on the left (4 slices) has hypoattenuation (arrows) of cortical and sub-cortical (caudate and lentiform) grey matter. These areas are irreversibly injured. The patient on the right has evidence of isolated sulcal effacement (arrows). This represents an increase in cerebral blood volume and the tissue is potentially salvageable. The Alberta Stroke Program Early CT Score (ASPECTS). The $M C A$ territory is divided into 10 regions. A normal ASPECT score is 10. A single point is removed for ischemic change in any one area. C, Caudate; L; Lentiform Nucleus; IC; Internal Capsule; I, Insular Cortex; M1-M6, cortical regions.

\section{Imaging the Parenchyma in Acute Ischemic Stroke: Non- Contrast CT}

Non-contrast computed tomography remains the workhorse of acute stroke patient workup in most institutions. Advantages include the fact that it can be performed in a matter of minutes and images can be viewed and interpreted as they are acquired. These are extremely important factors, as the effectiveness of thrombolysis, which is the only proven acute stroke therapy, has been shown repeatedly to be highly time sensitive. ${ }^{2}$ Indeed, within 3 and more recently 4.5 hours of symptom onset, it has been shown that parenchymal imaging with NCCT to rule out intracranial hemorrhage and/or extensive early ischemic changes is sufficient information upon which to base a thrombolysis decision. ${ }^{3,4}$ This likely reflects the fact that the majority of patients, within this early time period after symptom onset have some degree of penumbral tissue.

Parenchymal changes seen on NCCT in acute ischemia include subtle focal swelling/sulcal effacement and hypoattenuation (Figure 1). Comparative CT/MRI studies indicate these are distinctly different phenomenon from a pathophysiological and prognostic viewpoint.5,6 Hypo-attenuation represents an increase in tissue water content, which results in a reduction of tissue density. This occurs following a series of compartmental fluid shifts (intravascular $\rightarrow$ interstitial $\rightarrow$ intracellular), that ultimately result in additional water within the brain. ${ }^{7}$ The fluid shifts follow bio-energetic failure, i.e. arrest of ATP-dependent sodium-potassium exchange pumps (cytotoxic edema). It is also possible that very early hypo-attenuation may result from a decrease in cerebral blood volume (CBV), particularly in the capillary and venous circulation. ${ }^{8}$ Regardless of the precise pathophysiology, it is clear that hypo-attenuated regions represent irreversibly injured tissue, that is destined for infarction. ${ }^{5,6,9}$

Isolated sulcal effacement actually results from the compensatory increase in $\mathrm{CBV}$ that occurs in penumbral tissue. $5,6,10,11$ This is most likely a homeostatic response to ischemia. Vasodilatation and microcirculatory changes that temporarily protect tissue from infarction also result in sulcal compression as $\mathrm{CBV}$ increases. The fate of this tissue is variable and dependent on reperfusion. Isolated sulcal effacement should not be considered a contraindication to thrombolysis. Indeed, it is an indication for treatment, as the associated elevation of CBV has been shown to be a characteristic of penumbral tissue, amenable to salvage with reperfusion. ${ }^{12-14}$ Unfortunately, this type of ischemic change does not occur frequently enough to be relied on as a marker of penumbral tissue.

The Alberta Stroke Program Early CT Score (ASPECTS) is a validated semi-quantitative scale useful for assessing the extent of ischemic changes within the middle cerebral artery (MCA) territory (Figure 1). ${ }^{15,16}$ This is a negative ordinal scale, in which normal appearing brains are scored as ' 10 ' and those with ischemic changes involving the entire MCA territory are rated ' 0 '. Currently ASPECTS does not differentiate hypoattenuation from sulcal effacement, although a modification of the scoring system has been suggested, based on the different underlying pathophysiology of these two CT patterns. ${ }^{5}$ The ASPECT score is an excellent teaching tool and it encourages a systematic approach to assessing acute CT scans for ischemic changes.

Early ischemic parenchymal CT changes, in particular hypoattenuation, in acute stroke have been found to be predictive of outcome. ${ }^{9,11}$ Patients presenting with extensive areas of hypoattenuation, i.e. low ASPECT scores, have a poor prognosis, regardless of whether or not they are treated with thrombolytic 
agents. It has been demonstrated that ASPECTS scores $>7$ predict a better outcome in patients treated with thrombolysis. ${ }^{17}$ Although studies have not been consistent, there is also evidence that ischemic changes are related to the probability of hemorrhagic transformation. ${ }^{9,17,18}$ The risk of hemorrhage is likely increased, but this is also dependent on timing and extent of reperfusion and is therefore difficult to predict. The lack of a consistent relationship between the extent of early ischemic changes and thrombolysis related hemorrhagic complications likely reflects the multi-factorial nature of the latter. While hemorrhage remains difficult to predict, the probability of this complication is increased in patients with large and established infarct signs on pre-treatment CT scans.

\section{Imaging the Parenchyma in Acute Ischemic Stroke: MRI Conventional MRI Sequences}

In order to interpret MRI in acute stroke patients, it is helpful to have a rudimentary understanding of sequence acquisition principles. Interested readers are referred to more comprehensive MRI texts for additional information. ${ }^{19,20}$ Magnetic resonance imaging signal acquisition can be summarized in four basic steps. Protons are initially aligned in a magnetic field. The protons have a natural magnetic spin, which results in precession about the longitudinal axis of this magnetic field. Protons are then excited with a radiofrequency (RF) pulse. This is followed by proton 'relaxation' (two types), resulting in a radiofrequency signal that is 'read out' by the receiver coil, which is essentially an antenna, of the MRI. The fourth step is construction of an image through spatial and frequency encoding of this signal.

In spin echo (SE) imaging, protons are initially excited with a RF pulse transmitted at $90^{\circ}$ to the alignment of the protons in the magnetic field. These protons are now in a higher energy state and no longer aligned with the magnetic field axis. In addition, the precession of the protons is temporarily synchronized or 'in phase'. Proton relaxation takes two forms; longitudinal or spinlattice and transverse or spin-spin (phase) relaxation, which are the basis of the T1 and T2 signals respectively. These two forms of relaxation occur concurrently, although $\mathrm{T} 1$ effects are seen earlier after excitation. Therefore, $\mathrm{T} 1$ signals are maximized by reducing the time between excitation and signal readout (echo time; TE). Conversely, T2-weighted images are generated using a longer TE.

Normally, SE images also utilize a second $180^{\circ}$ degree rephasing RF pulse, which serves to 're-focus' images, making them less susceptible to field inhomogeneities which occur at the interface between tissues with different susceptibilities, such as bone and air or even cerebrospinal fluid and grey matter. It is this

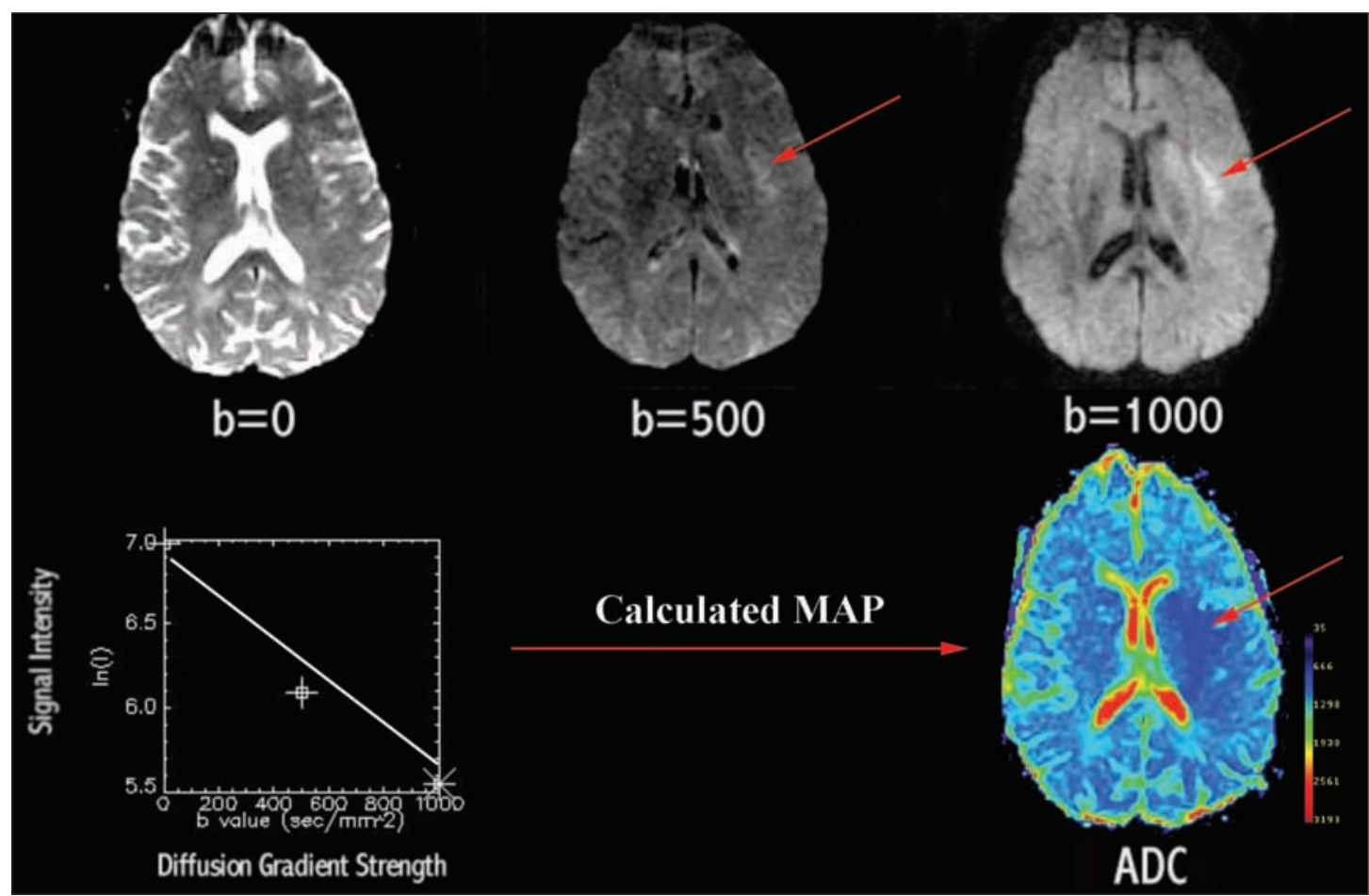

Figure 2: Diffusion-weighted image (DWI) demonstrating acute bio-energetic compromise in an ischemic stroke patient. Escalating ' $b$ ' values correspond to increasing diffusion gradient strength. The $b=0$ image is T2-weighted and does not demonstrate ischemic changes. The $b=1000$ image (aka trace or isotropic image) demonstrates the compromised tissue (arrow). The Apparent Diffusion Coefficient (ADC) maps are calculated on a voxel wise basis, using at least two signal intensities obtained with varying diffusion gradient strengths and the Stesjkal-Tanner equation. ADC units are $x$ $10^{-6} \mathrm{~mm}^{2} / \mathrm{s}$. 
second RF pulse which produces the relaxation 'echo,' for which SE images are named. This second RF pulse preserves the MRI signal, improving image contrast, but also makes detection of magnetic inhomogeneities more difficult. The T2-weighted images which are acquired without a $180^{\circ}$ re-phasing pulse are known as $\mathrm{T} 2 *$ sequences and these are very susceptible to any inhomogeneities in the magnetic field. Field inhomogeneities also result from any substances with unpaired electrons, which are referred to as paramagnetic. The $\mathrm{T} 2 *$ images are therefore sensitive to the presence of any paramagnetic materials and are an example of susceptibility-weighted sequences.

Gradient Recalled Echo, sometimes referred to simply as Gradient Echo, images (GRE) are generated in a different manner to the conventional SE technique described above. Protons are excited with an RF pulse of less than $90^{\circ}$, which permits more frequent excitations (decreased repetition time; TR). Unlike SE, an echo is generated using a biphasic magnetic gradient, which first de-phases and then re-phases protons, and gives the sequence its name. The primary advantage of this sequence is that image acquisition time is shorter. Gradient Recalled Echo sequences are also more susceptible to paramagnetic effects, making them particularly useful for detection of hemorrhage (see below). Gradient Recalled Echo sequences obtained without a re-phasing gradient, i.e. GRE T2* images, are used in perfusion-weighted imaging (PWI).

\section{Echoplanar Imaging}

Conventional MRI sequences rely on multiple RF excitations to produce numerous echoes, which are used to generate images. Echoplanar Imaging is a technique which allows sampling of an entire volume of tissue with a single RF pulse excitation. This is accomplished through high performance gradients, which are cycled on and off during a single period of proton relaxation. This ultra-fast technique has been revolutionary for acute stroke assessment, as it allows imaging of physiological phenomena, including water diffusion and blood flow.

\section{Ischemic Changes: Diffusion-weighted Imaging}

Conventional (T1 and T2) MRI sequences are not more sensitive than CT for the detection of hyper-acute ischemic changes. The pathophysiological changes underlying increases in T2 signal intensity are the same as those that result in hypoattenuation on CT, i.e. edema. In contrast, diffusionweighted imaging (DWI) demonstrates areas of bio-energetic compromise-that is tissue where sodium-potassium ATPase activity has failed. This results in compartmentalization of water, within the intracellular and extracellular spaces. Diffusionweighted imaging employs serial de-phasing and re-phasing gradients, known as diffusion-gradients, to image the movement of protons (water) in space (diffusion). Protons that are not moving, i.e. have restricted diffusion, are associated with higher signal, i.e. hyper-intensity, on DWI. Under ischemic conditions, DWI restriction occurs within minutes ${ }^{21}$ and persists for 7-14 days, at which point cell membranes break down and water is no longer sequestered. Diffusion-weighted imaging demonstrates even limited regions of early ischemia with high sensitivity and is markedly superior to CT in this respect. ${ }^{22,-23}$ It is important to note that while ischemia is the most common cause of diffusion restriction, other pathological processes can also result in DWI changes, including acute demyelination, neoplasm and infection. ${ }^{24-27}$

The Apparent Diffusion Coefficient (ADC) is derived from the raw diffusion-weighted images. The ADC is a quantitative measure of the rate of proton, and therefore water, movement. ${ }^{28}$ An estimate of the speed of water diffusion is obtained by comparing signal intensities at varying diffusion gradient strengths. The strength of these gradients is denoted by the symbol 'b.' Clinical DWI is normally obtained with a b-value of 1000. Gradients are applied in a number of directions (generally at least three) and the signal averaged to form a directionindependent (isotropic) image (sometimes referred to as the 'trace' or 'b 1000' image). When diffusion gradients are not applied $(b=0)$, a T2-weighted image is obtained. Intermediate gradients (i.e. $b=500$ ) are also often applied. Apparent Diffusion Coefficient maps are obtained by applying an equation (StejskalTanner) to the signal intensities with two or more $b$ values for each voxel. ${ }^{29}$ Maps are simply intensity, or colour, coded to reflect relative values derived from this application (Figure 2). These maps are useful for identifying areas which appear hyperintense on DWI secondary to an artifact known as 'T2shine through', rather than true bio-energetic failure.

In areas of more profound energetic compromise and sequestration of water molecules, ADC values are lower. Only tissue with moderate decreases in ADC, generally less than $15 \%$ of normal, sometimes escape infarction. ${ }^{28}$ This phenomenon is known as DWI reversal. ${ }^{30}$ Although ADC thresholds for infarction and reversal have been identified, they have not yet proven to be clinically useful. ${ }^{31}$ This is partially due to the fact that ADC thresholds vary with duration of symptoms and the extent of reperfusion, whether spontaneous or secondary to thrombolytic therapy. ${ }^{32}$ Most commonly serial studies of ischemic stroke reveals a pattern where ADC appears to

Table: Appearance of intraparenchymal blood on MRI

\begin{tabular}{c|c|c|c|c}
\hline $\begin{array}{c}\text { Time from } \\
\text { Onset }\end{array}$ & $\begin{array}{c}\text { Hematoma } \\
\text { Constituents }\end{array}$ & T1 & T2 & $\begin{array}{c}\text { SWI } \\
\text { (GRE/T2*) }\end{array}$ \\
\hline $\begin{array}{c}\text { Hyper-acute } \\
\text { (<24 hours) }\end{array}$ & $\begin{array}{c}\text { Oxyhemoglobin } \\
\text { Deoxyhemoglobin } \\
\text { Plasma }\end{array}$ & $\leftrightarrow$ & $\begin{array}{c}\text { Mixed: } \\
\downarrow \text { (rim) } \\
\uparrow \text { (center) }\end{array}$ & $\downarrow$ \\
\hline $\begin{array}{c}\text { Acute } \\
\text { (1-3 days) }\end{array}$ & $\begin{array}{c}\text { Deoxyhemoglobin } \\
\text { (Increases with } \\
\text { time) } \\
\text { Plasma }\end{array}$ & $\leftrightarrow$ & $\downarrow$ & $\downarrow$ \\
\hline $\begin{array}{c}\text { Early Sub- } \\
\text { acute } \\
\text { (3-7 days) }\end{array}$ & $\begin{array}{c}\text { Intracellular } \\
\text { Methemoglobin } \\
\text { Plasma }\end{array}$ & $\uparrow$ & $\downarrow$ & $\downarrow$ \\
\hline $\begin{array}{c}\text { Late Sub- } \\
\text { acute } \\
\text { (7-14 days) }\end{array}$ & $\begin{array}{c}\text { Extracellular } \\
\text { Methemoglobin }\end{array}$ & $\uparrow$ & $\uparrow$ & $\downarrow$ \\
\hline $\begin{array}{c}\text { Chronic } \\
\text { (>2 weeks) }\end{array}$ & $\begin{array}{c}\text { Hemosiderin } \\
\pm \text { CSF cavity }\end{array}$ & $\downarrow$ & $\downarrow$ & $\downarrow$ \\
\hline
\end{tabular}

SWI=Susceptibility-weighted images; GRE=Gradient Recall Echo 


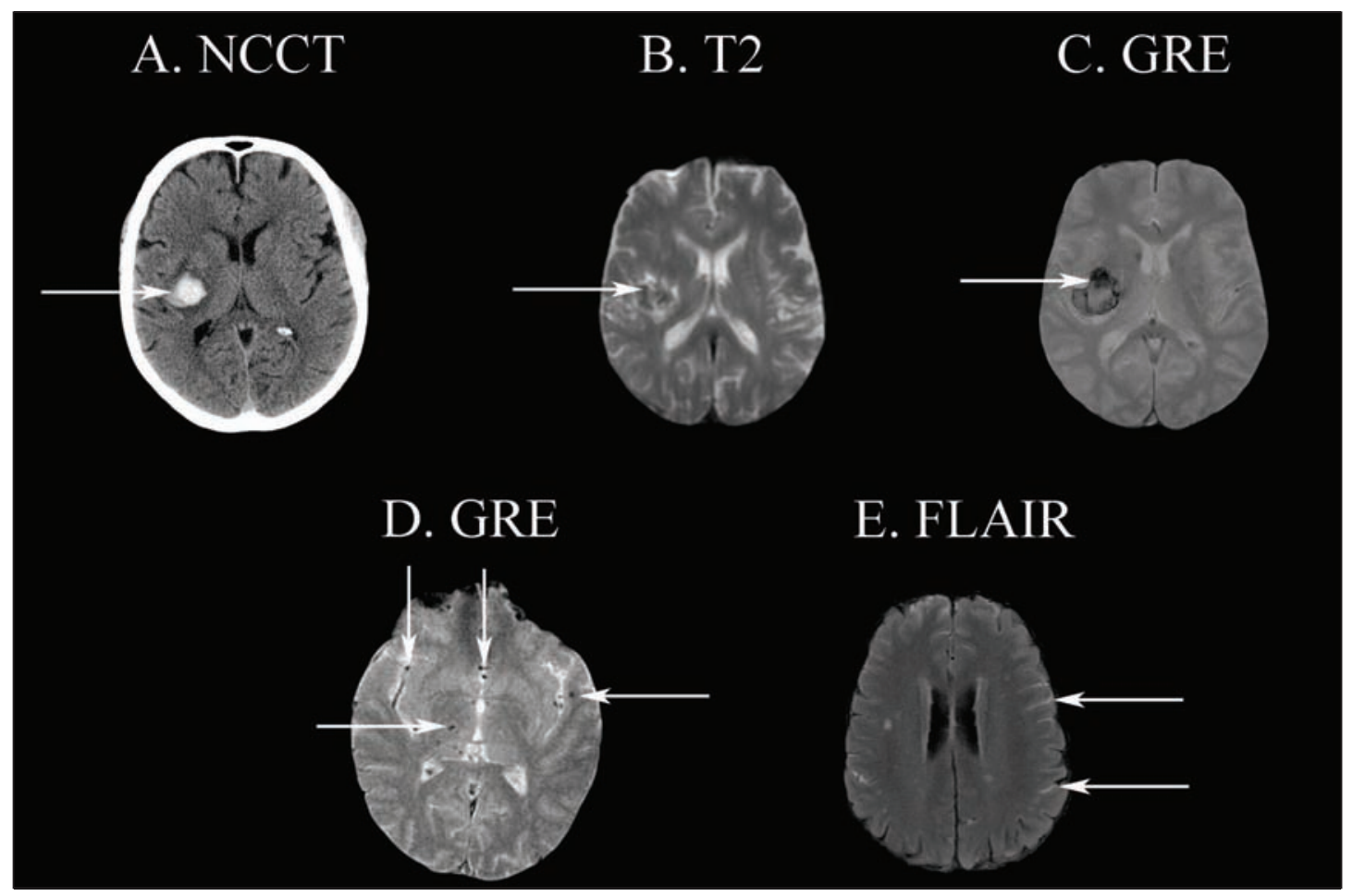

Figure 3: A-C. Acute primary intracerebral hemorrhage (ICH) imaged with CT, T2-weighted (T2) and gradient recalled echo (GRE) MRI two hours after symptom onset. Acute blood appears hypointense on both MRI sequences, due to the paramagnetic effects of deoxyhemoglobin, which forms initially at the margin of the hematoma (arrows). Edema and fluid components of the hematoma appear bright on the T2-weighted images. D. GRE demonstrating cerebral microbleeds (horizontal arrows). Vertical arrows demonstrate flow voids (arteries). E. Fluid attenuated inverse recovery (FLAIR) demonstrating hyperintense signal due to acute subarachnoid blood (arrows) following aneurysmal rupture. NB: Studies from three different patients are shown $(A-C, D$ and $E)$.

normalize as cell membranes break down, but the tissue ultimately goes on to infarct, a phenomenon known as 'DWI pseudo-normalization'. In gliotic areas, ADC values will eventually rise to levels comparable to that seen in other CSF spaces.

\section{Intracerbral Hemorrhage (ICH) and MRI}

One of the obstacles to routine hyperacute stroke assessment with MRI alone, is reluctance on the part of clinicians to consider MRI a reliable tool for differentiating hyperacute ICH from ischemia. This is based on the ease of identification of blood on CT scans, as an area of hyperdensity, as well as the perceived difficulty associated with visualization of acute hemorrhage on MRI. Four factors have been identified with the potential to alter MRI signal intensity in the presence of intraparenchymal blood. These are increased red cell density, clot matrix formation, decreasing cellular hydration and finally blood deoxygenation and breakdown. ${ }^{33}$ While all of these ultimately affect the MRI signal, it is the latter which is most important, due to the susceptibility properties of these blood components as well as their effects on relaxivity of adjacent water molecules (protons). Paramagnetic blood constituents and metabolic products include deoxyhemoglobin, methemoglobin and hemosiderin. In contrast, oxyhemoglobin is diamagnetic and therefore does not result in changes in MRI signal. In addition to oxyhemoglobin and deoxyhemoglobin, acute blood also contains significant amounts of water in the form of plasma, which is heavily T2-weighted. Thus, acute intraparenchymal blood has a mixed signal on traditional T2-weighted images (Figure 3). ${ }^{33,34}$

In hyper-acute $\mathrm{ICH}$, the susceptibility effects are first observed at the periphery of the hematoma. ${ }^{35}$ This is related to formation of deoxyhemoglobin and magnetic field inhomogeneities at the interface with surrounding normal diamagnetic tissue. This is useful in delineating the boundary of the hematoma, from the rim of peri-hematomal edema, as the latter is always hyperintense on T2-weighted images. It is important to recognize that measurements of hematoma volume made on MRI will tend to over-estimate the true volume. ${ }^{36}$ Susceptibilityweighted sequences including GRE $\mathrm{T} 2 *$, which are more sensitive to the paramagnetic effects of deoxyhemoglobin, make acute blood even more obvious on MRI (Figure 3). ${ }^{33,37-39}$

Magnetic resonance imaging signal changes on GRE, T1 and T2-weighted images can also be used to estimate the age of intracranial blood. In addition to the increasingly hypointense T2 signals seen with progressive deoxygenation, after 72 hours T1 signal intensity increases due to the presence of methemoglobin (Table). After approximately seven days, the T2 signal intensity will also increase, as red blood cells are lysed. Eventually, both 
T1 and T2 signals are significantly decreased, as only hemosiderin is left as a remnant of the hematoma. Depending on the size of the hematoma, a CSF filled cavity, which is heavily T2-weighted, may also be evident.

A number of studies have demonstrated that acute $\mathrm{ICH}$ can be readily diagnosed and differentiated from ischemia, even in trainees with very little experience..$^{40,41}$ Magnetic resonance imaging and CT appear to have equivalent sensitivity for the detection of acute hemorrhage. Thus, in centres where it is logistically feasible, MRI is used as the initial and often only imaging investigation for acute stroke syndrome patients.

Magnetic resonance imaging is markedly superior for the detection of chronic blood, which cannot be differentiated from any other cause of gliosis on CT scan. This includes identification of cerebral microbleeds (CMBs), defined as hypointensities, less than $5 \mathrm{~mm}$ in diameter, most easily identified on susceptibility-weighted sequences (Figure 3). ${ }^{42-45}$ These foci of MR signal loss represent deposits of hemosiderin within macrophages, resulting from past bleeding episodes. Histopathological analysis demonstrates a strong association with microangiopathy secondary to lipo/fibrohyalanosis and amyloid deposition. ${ }^{43}$ The incidence of CMBs in populations without neurological disease has been estimated to be between 4 and $6 \% .^{46,47}$ The prognostic value of CMBs in therapeutic decision making remains unclear. It has been proposed that CMBs may be predictors of symptomatic hemorrhagic transformation following thrombolytic therapy for acute ischemic stroke. Indeed, there have been reports of increased rates of intracerebral hemorrhage following both intra-arterial and intravenous therapy in patients with CMBs. ${ }^{48,49}$ This association has been particularly compelling in cases where the hemorrhage has appeared to occur at the site of a CMB, sometimes remote from the ischemic region. ${ }^{49}$ Cerebral microbleeds may also be useful in stratifying risk-benefit ratios for patients being considered for long-term anti-coagulation. At this point, however, the evidence that $\mathrm{CMBs}$ predict hemorrhagic complications of thrombolytic or anticoagulant therapy is restricted to case reports. Another study demonstrated that the presence of CMBs independently predicted hemorrhagic transformation of ischemic infarcts, irrespective of treatment with tPA. ${ }^{50}$ Thus, while CMBs are likely to be associated with increased risk of early hemorrhage after ischemic stroke, it is not clear that thrombolysis necessarily significantly adds to this risk. Indeed, a preliminary report from an ongoing trial assessing the ability of MRI to predict the response to ischemic stroke thrombolysis three to six hours after onset indicated no increased risk of symptomatic or asymptomatic hemorrhage in patients with CMBs ${ }^{51}$ Assessing the absolute risk that CMBs represent to potential thrombolysis candidates will require a very large number of patients, but at this point it does not appear to be excessive.

A final consideration in the assessment of an MRI performed in an acute stroke patient is the diagnosis of subarachnoid hemorrhage. Blood within the subarachnoid space has a very different MR appearance than intraparenchymal hemorrhage. Although not visible on standard or even GRE sequences, acute subarachnoid blood can be visualized with Fluid Attenuated Inverse Recovery (FLAIR) sequences. The FLAIR sequence has a long echo (readout) time, making it heavily T2-weighted, but the normally high CSF signal is effectively nulled by a second
RF pulse, timed to match the longitudinal relaxation properties of CSF. ${ }^{52}$ Acute subarachnoid blood appears hyperintense on FLAIR images (Figure 3). The source of this high signal appearance is thought to be related to elevated protein concentrations, which alter the magnetization properties of CSF. The differential diagnosis therefore includes proteinaceous exudates, which can be seen in other CSF space disease conditions, including meningitis. A number of systematic studies have confirmed that MRI is superior to CT for the detection of subarachnoid blood, particularly when there is a delay to imaging and/or the hemorrhage volume is small. ${ }^{53-57}$ In intubated and sedated patients, the effects of propofol and high flow oxygen administration must be considered, as both have been associated with elevated FLAIR signal intensity within the CSF. ${ }^{58,59}$ This is a transient and benign phenomenon.

\section{Imaging the Cerebral Vasculature}

Parenchymal imaging does not provide reliable information related to vessel status. NCCT may reveal a hyperdense artery sign, which predicts acute thrombus with high specificity, but this is present only in a minority of acute stroke patients (Figure 4). ${ }^{60}$ Intravascular blood is normally visible on parenchymal MRI sequences due to the effects of flow, which disrupt signal acquisition, resulting in the 'voids' familiar to most clinicians. Fortunately, intracranial vessels can be imaged with both MRI (Magnetic Resonance Angiography; MRA) and CT (CT Angiography; CTA). Both techniques are limited to demonstration of larger intracranial arteries, although CTA does have superior spatial resolution, permitting visualization of some medium sized arteries. Digital subtraction catheter angiography remains the investigation of choice for assessing smaller arteries, such as in cases of suspected vasculitis.

Intracranial MRA can be performed without the use of contrast agents. The most commonly utilized technique is 'Time of Flight' (TOF) imaging, centred on the circle of Willis. This MR sequence saturates tissue with repetitive RF pulses, resulting in a loss of signal in all areas except those with moving protons, i.e. flowing blood (Figure 4). The primary limitation of this technique is that regions of slow and/or turbulent arterial flow, such as at a stenosis, may have the appearance of an occlusion on MRA. ${ }^{61,62}$ Another sequence, known as phase contrast MRA, is sensitive to flow velocities and therefore can provide both direction and flow rate information. Signal-to-noise ratios are generally lower than TOF, however and outside of specialized centres, this technique is used less routinely. ${ }^{61}$

Contrast-enhanced MRA (CE MRA) images are based on the T1-effects of gadolinium within vessels (Figure 4). Automatic bolus detection algorithms make it possible to time image acquisition with that of the maximum arterial concentration of the contrast agent induced T1-shortening effects. Contrastenhanced MRA reduces most of the artefacts of TOF MRA and has improved signal-to-noise ratio, permitting assessment of somewhat smaller vessels. ${ }^{63}$ In addition, CE MRA is more likely to indicate low flow in stenotic areas, that may actually appear occluded on TOF MRA. ${ }^{62}$ Contrast-enhanced MRA is therefore useful in the evaluation of the extracranial circulation for potential stroke etiology, i.e. carotid stenosis. However, even CE MRA is prone to over-estimation of the degree of carotid stenosis. ${ }^{64}$ 


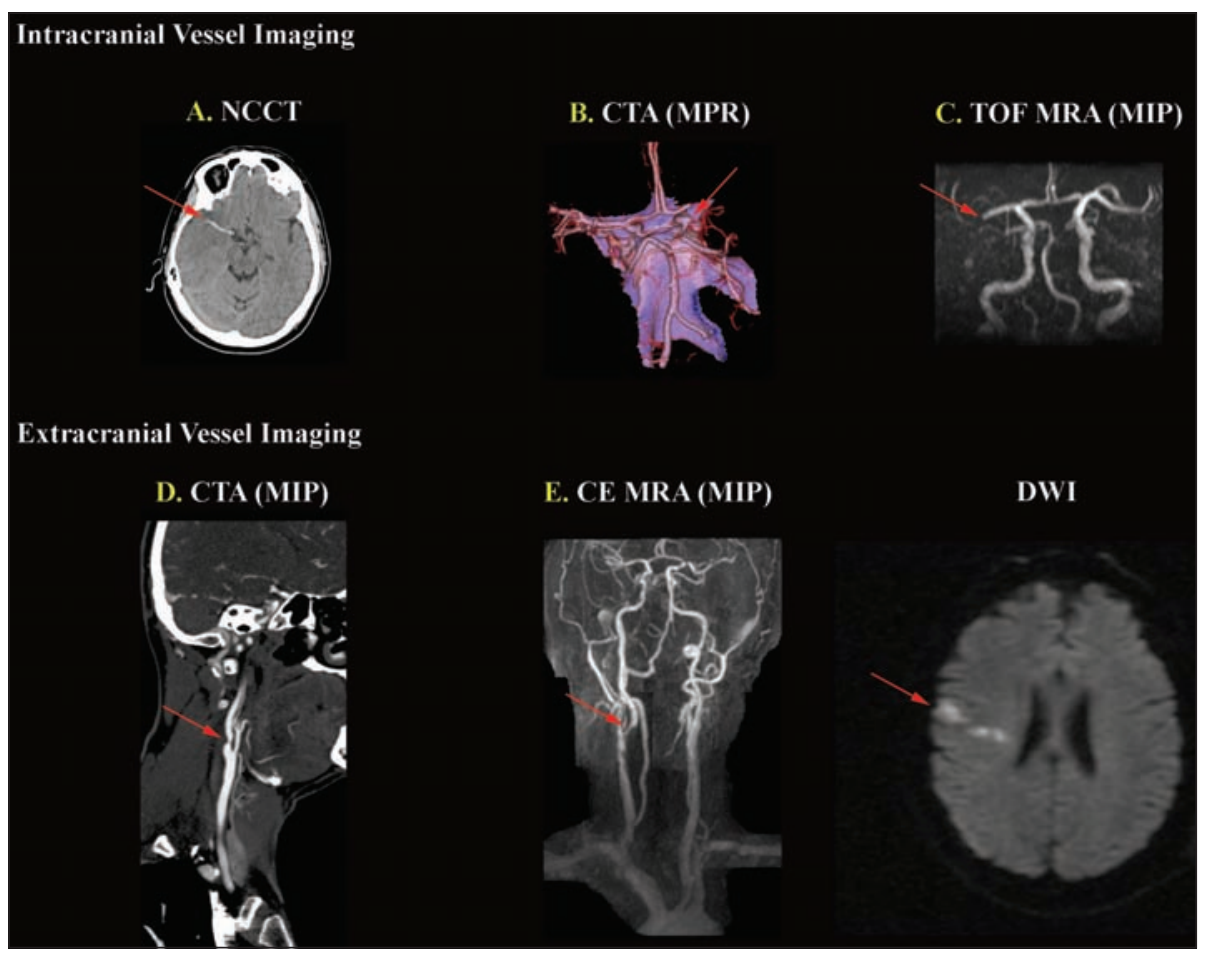

Figure 4: Imaging intracranial and extracranial arterial vessels. A. Evidence of arterial occlusion on non-contrast CT (NCCT) in the form of a hyperdense MCA sign. B. CT angiography (CTA); Multi-planar reconstruction (MPR) demonstrating right distal ICA occlusion. C. Time of Flight Magnetic Resonance Angiography (TOF MRA); Maximum Intensity Projection (MIP) demonstrating distal MCA occlusion. D. Extracranial CTA MIP demonstrating ICA stenosis. E. Extracranial MRA MIP demonstrates stenosis with lower spatial resolution, although combined with Diffusion-weighted imaging (DWI), it is clear that this lesion is symptomatic. NB: Studies from 5 different patients are shown $(A-E)$.

Unlike MRI, CT evaluation of the vasculature always requires an intravenous injection of iodinated contrast, delivered via a power injector. A CTA is acquired using a bolus tracking technique. Image acquisition is timed to follow or 'track' the contrast as it moves through the arterial circulation. An acute stroke protocol CTA should ideally include all vessels from the aortic arch to the cranial vertex. ${ }^{65}$ Acute arterial occlusion or stenosis is readily identified on both CTA source images as well as re-constructed maximal intensity projections (MIP; Figure 4) ${ }^{66}$ The latter simply indicates the maximum intensity obtained within each voxel, which is generally the point of highest contrast concentration, on a single image.

Comparative studies with catheter angiography indicate that CTA detects intracranial and extracranial large artery occlusions and stenoses with high sensitivity and specificity. ${ }^{66,67}$ In addition, CTA has been shown to be very useful in differentiation of acute transient ischemic attack (TIA) and stroke from patients with mimic conditions, such as migraine. In patients with intracerebral hemorrhage, CTA permits rapid identification of underlying structural lesions, with high sensitivity and specificity. ${ }^{68}$ Finally, demonstration of acute focal intrahematoma contrast enhancement ('spot sign'), using CTA in intracerebral hemorrhage patients, has been shown to be predictive of ongoing bleeding and hematoma expansion. ${ }^{69}$ The only disadvantages associated with CTA are related to complications arising from iodinated contrast use and an increased effective radiation dose, both of which are discussed in Part II. ${ }^{70}$

\section{Imaging Cerebral Blood Flow}

Regional Cerebral blood flow (rCBF) refers to the volume of blood flowing to a portion of the brain over time. It is measured in $\mathrm{ml} / 100 \mathrm{~g} / \mathrm{min}$ and normally varies with tissue type (grey matter $40-60 \mathrm{ml} / 100 \mathrm{~g} / \mathrm{min}$; white matter $22 \mathrm{ml} / 100 \mathrm{~g} / \mathrm{min}$ ) as well as tissue metabolic requirements. It is important to note that blood vessel imaging is not synonymous with the measurement of rCBF. Tissue flow is dependent on collateral flow and microcirculatory changes, which are not reflected in MRA/CTA or transcranial Doppler ultrasound data. The latter provides only velocity information within a single artery and this is not a reliable surrogate for $\mathrm{rCBF}$.

It is possible to measure $\mathrm{rCBF}$ in acute stroke patients using MRI or CT at the same time parenchymal and vessel images are obtained. Measurement of flow with both modalities is based on non-diffusible tracer kinetics and the central volume principle. An intravascular tracer agent is injected as a rapid bolus (generally $5 \mathrm{ml} / \mathrm{s}$ via $18 \mathrm{~g} \mathrm{IV}$ ), which is then 'tracked'. This is 


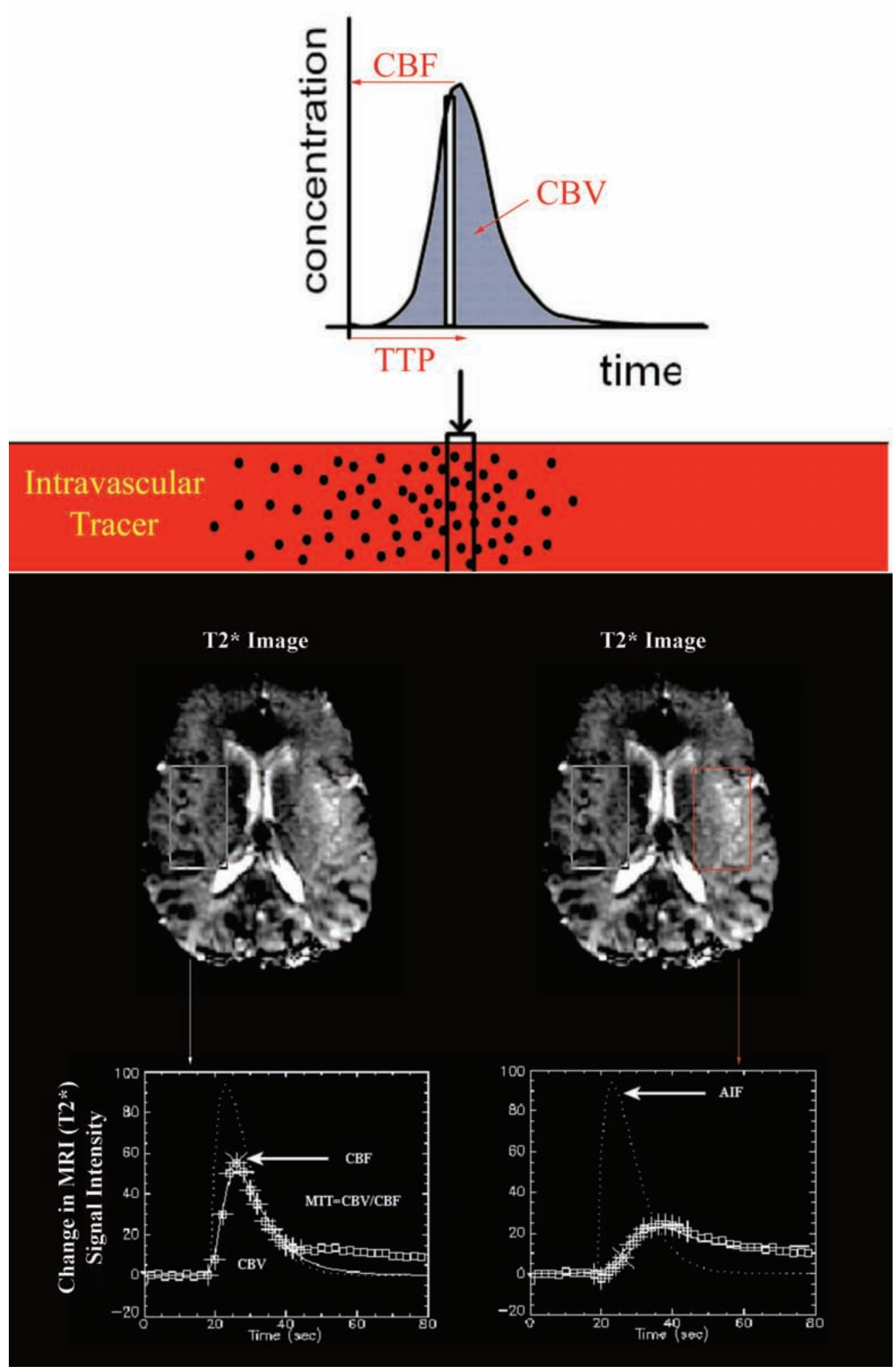

Figure 5: Imaging cerebral blood flow using either MRI or CT is based on non-diffusible tracer kinetics and the central volume theorem. A contrast agent (gadolinium in the case of MRI and iodine in the case of $C T$ ) is injected into the vasculature. The serial effect of this agent on tissue contrast as it transits the cerebral circulation is used to plot an intensity-time curve. The curves shown are from PWI acquisition in an acute stroke patient (left hemisphere is affected). Cerebral Blood Flow (CBF) is proportional to the amplitude of the curve. Cerebral Blood Volume (CBV) is proportional to the area under the curve. Time domain measures including Time to Peak (TTP) and Mean Transit Time (MTT) are prolonged. A deconvolution algorithm based on an arterial input function (AIF), in this case taken from the middle cerebral artery, can be used to ameliorate errors introduced by delay and dispersion of the contrast agent prior to arrival in the cerebral circulation. 
similar to the process utilized in CTA acquistion, except that signal intensity, which is proportional to tracer concentration as it transits the cerebral circulation, is measured sequentially and plotted as a function of time (Figure 5). Perfusion 'images' are in fact all parametric maps, based on the concentration-time curves generated in this way. Cerebral Blood Flow (CBF) is proportional to the amplitude of the signal intensity time curve, while Cerebral Blood Volume (CBV) is proportional to the area under the curve. ${ }^{71}$ Estimates of tissue perfusion are also provided by the Time to Peak (TTP) of the curve, which are actually the most commonly utilized maps in 'real time' perfusion assessment. Voxel-wise values for each parameter are derived from the concentration-time curve and then assigned a colour code or intensity value, similar to the process used for creating ADC maps (Figure 6).

Bolus tracking perfusion imaging using MRI and CT is prone to errors introduced by delay and dispersion of the tracer bolus prior to arrival in the brain, as the central volume principle is based on the assumption that the injection is instantaneous. While an instantaneous infusion of contrast into the cerebral circulation is not possible, the effect of such an injection can be estimated using a reference arterial input signal and a mathematical procedure known as deconvolution (Figure 5). ${ }^{72,73}$ Following deconvolution, a number of additional flow maps can be generated including Tmax (TTP after deconvolution), and Mean Transit Time (MTT, calculated as CBV/CBF).

\section{Perfusion-Weighted Imaging (PWI)}

Perfusion-Weighted Imaging is acquired using gadolinium as the tracer agent. The base MR images are susceptibilityweighted - that is sensitive to the effects of paramagnetic agents, including gadolinium). A series of these images (known as T2*) are obtained every one to two seconds during an injection of gadolinium. As contrast transits the cerebral circulation, MRI $\mathrm{T} 2 *$ signal intensity successively decreases and then returns to normal. The change in signal intensity is then plotted as a

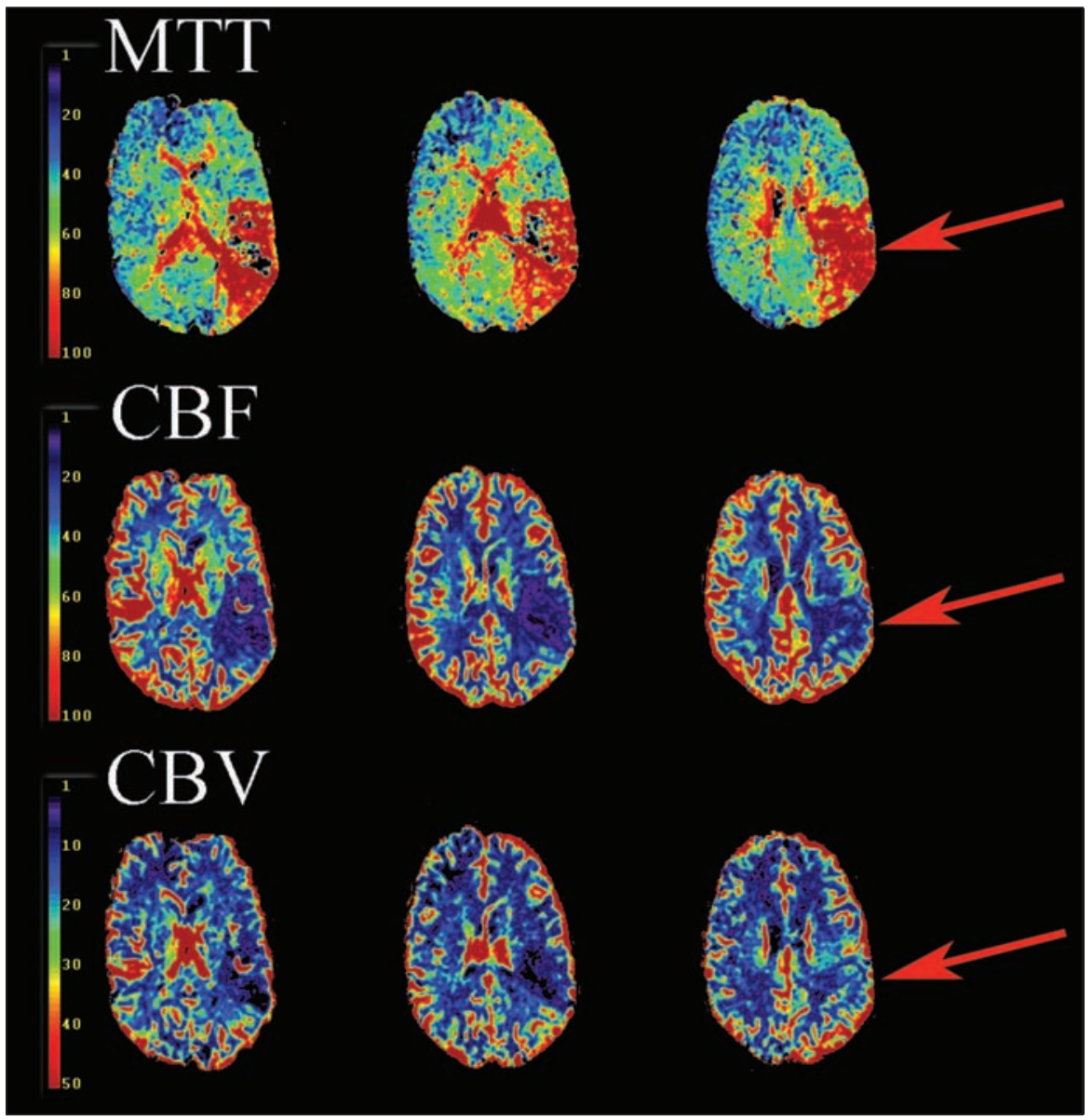

Figure 6: Examples of PWI maps in an acute ischemic stroke patient (left hemisphere symptoms) imaged 5.5 h after symptom onset. MTT (Mean Transit Time, units are 1/10th s) is prolonged in the ischemic region (arrow). Time to Peak and Tmax (not shown) are also prolonged in this region. CBF (Cerebral Blood Flow; ml/100 g/min) is decreased in this region. CBV (Cerebral Blood Volume; ml/100 g) is reduced in a smaller portion of the hypoperfused region, indicating an evolving infarct core. 
function of time (the signal-intensity time curve; Figure 5), and parametric maps (CBF, CBV, TTP, MTT, Tmax) are generated as described above. ${ }^{71}$ Thus, the term 'PWI' is an oversimplification. In the clinical setting, it is important to understand what type of map one is assessing and how to interpret it. The TTP, MTT and Tmax will all be prolonged in hypoperfused regions, due to delay in arrival and transit of the contrast, and this is generally indicated with hyper-intensity on the corresponding maps (Figure 6). Oligemic tissue will have low $\mathrm{CBF}$, which is generally mapped as a hypointense/dark area. A decrease in $\mathrm{CBV}$, seen in irreversibly injured tissue, is also generally mapped as a hypointensity.

A shortcoming of PWI is that gadolinium concentration and T2* intensity are not linearly related, making absolute quantification of $\mathrm{CBF}$ impossible. This is really a theoretical concern, however, as $\mathrm{CBF}$ thresholds for infarction have been shown to be highly dependent on the duration of oligemia and reperfusion effects. ${ }^{12}$ Furthermore, it is possible to obtain quantitative flow estimates by normalizing PWI maps to a reference value, such as normal white matter, which has a constant flow of $22 \mathrm{ml} / 100 \mathrm{~g} / \mathrm{min}^{74}$

\section{CT Perfusion Imaging (CTP)}

Computed tomogram perfusion imaging utilizes standard non-ionic iodinated contrast as the tracer agent to measure CBF. The transit of a bolus of IV contrast is traced by its serial affect on x-ray hypo-attenuation. ${ }^{75}$ The change in signal intensity, measured in Hounsfield units, after contrast media injection is proportional to the density of tissue and therefore the concentration of contrast at each time point. In this way, tissue time-density curves, which are very similar to the signal intensity time curves of PWI, are generated for each voxel. Computed tomogram perfusion imaging maps (CBF, CBV, TTP, MTT, Tmax) are then generated based on this time-density curve (Figure 7). Parametric CTP maps are interpreted in the same way as those generated using PWI.

Unlike PWI, CTP provides reliable quantitative flow measures, as the relationship between iodinated contrast density and concentration is linear. ${ }^{75-78}$ Absolute measurements are obtained by scaling relative CTP values from each voxel to that obtained from a region of interest at the centre of the superior sagittal venous sinus (which is completely filled with contrast, and is assumed to have a CBV of $104 \mathrm{ml} / 100 \mathrm{~g}){ }^{75}$

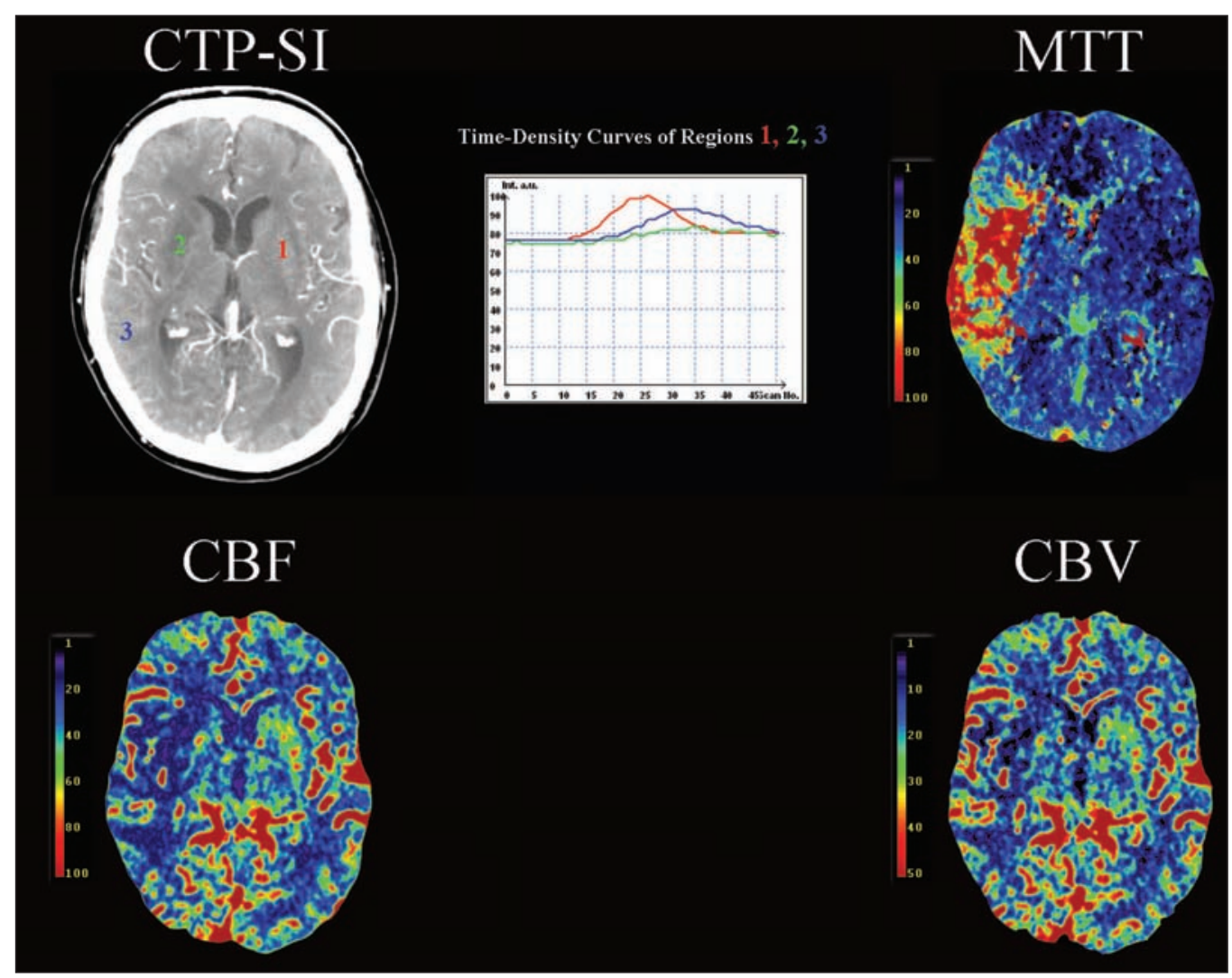

Figure 7: Example of CT Perfusion Images in a patient with acute ischemic stroke (right hemisphere) imaged 7 h after onset. The CTP-SI (source images) demonstrate contrast arrival (peak arterial phase shown). The time course of image intensity change for three regions is indicated by the time density curves for regions 1 (unaffected hemisphere), 2 (irreversibly injured tissue) and 3 (oligemic, but at risk tissue). Mean Transit Time (MTT; $1 / 10 t h$ $s)$ is prolonged in the right hemisphere. Cerebral Blood Flow (CBF; $\mathrm{ml} / 100 \mathrm{~g} / \mathrm{min})$ is reduced in this area as well. Cerebral Blood Volume (CBV; $\mathrm{ml} / 100$ g) is reduced only in region 2. 


\section{Conclusion}

Imaging is a critical step in the diagnosis and management of stroke. Non-contrast computed tomography will continue to provide the basic information required for rapid treatment in many patients. Additional information relevant to the prognosis and management of the patient can be obtained with MRI or advanced CT. As the value of these additional investigations is proven, they should become more routine in the acute setting, ultimately allowing therapy to be tailored to the pathophysiology of individual stroke patients. The utility of advanced imaging in acute stroke patient care is discussed in the second part of this series.

\section{ACKNOWLEDGEMENTS}

Dr. Butcher is supported by New Investigator Awards and project grant funding from the Alberta Heritage Foundation for Medical Research, Canadian Institutes for Health Research and Heart and Stroke Foundations of Canada and Alberta, NWT, and Nunavut.

\section{REFERENCES}

1. Astrup J, Siesjo BK, Symon L. Thresholds in cerebral ischemia the ischemic penumbra. Stroke. 1981 Nov-Dec;12(6):723-5.

2. Hacke W, Donnan G, Fieschi C, Kaste M, von Kummer R, Broderick JP, et al. Association of outcome with early stroke treatment: pooled analysis of ATLANTIS, ECASS, and NINDS rt-PA stroke trials. Lancet. 2004 Mar 6;363(9411):768-74.

3. Tissue plasminogen activator for acute ischemic stroke. The National Institute of Neurological Disorders and Stroke rt-PA Stroke Study Group. N Engl J Med. 1995 Dec 14;333(24): 1581-7.

4. Hacke W, Kaste M, Bluhmki E, Brozman M, Davalos A, Guidetti $\mathrm{D}$, et al. Thrombolysis with alteplase 3 to 4.5 hours after acute ischemic stroke. N Engl J Med. 2008 Sep 25;359(13):1317-29.

5. Butcher KS, Lee SB, Parsons MW, Allport L, Fink J, Tress B, et al. Differential prognosis of isolated cortical swelling and hypoattenuation on CT in acute stroke. Stroke. 2007 Mar;38(3): 941-7.

6. Na DG, Kim EY, Ryoo JW, Lee KH, Roh HG, Kim SS, et al. CT sign of brain swelling without concomitant parenchymal hypoattenuation: comparison with diffusion- and perfusionweighted MR imaging. Radiology. 2005 Jun;235(3):992-48.

7. Dzialowski I, Weber J, Doerfler A, Forsting M, von Kummer R. Brain tissue water uptake after middle cerebral artery occlusion assessed with CT. J Neuroimaging. 2004 Jan;14(1):42-8.

8. Kucinski T, Majumder A, Knab R, Naumann D, Fiehler J, Vaterlein $\mathrm{O}$, et al. Cerebral perfusion impairment correlates with the decrease of CT density in acute ischaemic stroke. Neuroradiology. 2004 Sep;46(9):716-22.

9. von Kummer R, Bourquain H, Bastianello S, Bozzao L, Manelfe C, Meier D, et al. Early prediction of irreversible brain damage after ischemic stroke at CT. Radiology. 2001 Apr;219(1):95-100.

10. von Kummer R. Early major ischemic changes on computed tomography should preclude use of tissue plasminogen activator. Stroke. 2003 Mar;34(3):820-1.

11. von Kummer R, Allen KL, Holle R, Bozzao L, Bastianello S, Manelfe C, et al. Acute stroke: usefulness of early CT findings before thrombolytic therapy. Radiology. 1997 Nov;205(2): 327-33.

12. Butcher K, Parsons M, Baird T, Barber A, Donnan G, Desmond P, et al. Perfusion thresholds in acute stroke thrombolysis. Stroke. 2003;34:2159-64.

13. Furlan M, Marchal G, Viader F, Derlon JM, Baron JC. Spontaneous neurological recovery after stroke and the fate of the ischemic penumbra. Ann Neurol. 1996 Aug;40(2):216-26.
14. Parsons MW, Pepper EM, Bateman GA, Wang Y, Levi CR. Identification of the penumbra and infarct core on hyperacute noncontrast and perfusion CT. Neurology. 2007 Mar 6;68(10): $730-6$.

15. Pexman JH, Barber PA, Hill MD, Sevick RJ, Demchuk AM, Hudon ME, et al. Use of the Alberta Stroke Program Early CT Score (ASPECTS) for assessing CT scans in patients with acute stroke. AJNR Am J Neuroradiol. 2001 Sep;22(8):1534-42.

16. Barber PA, Demchuk AM, Zhang J, Buchan AM. Validity and reliability of a quantitative computed tomography score in predicting outcome of hyperacute stroke before thrombolytic therapy. Lancet. 2000 May 13;355(9216):1670-4.

17. Hill MD, Rowley HA, Adler F, Eliasziw M, Furlan A, Higashida RT, et al. Selection of acute ischemic stroke patients for intraarterial thrombolysis with pro-urokinase by using ASPECTS. Stroke. 2003 Aug;34(8):1925-31.

18. Dzialowski I, Hill MD, Coutts SB, Demchuk AM, Kent DM, Wunderlich $\mathrm{O}$, et al. Extent of early ischemic changes on computed tomography (CT) before thrombolysis: prognostic value of the Alberta Stroke Program Early CT Score in ECASS II. Stroke. 2006 Apr;37(4):973-8.

19. Atlas SW. Magnetic resonance imaging of the brain and spine. 3rd ed. Philadelphia: Lippincott Williams \& Wilkins; 2002.

20. Hashemi RH, Bradley WG, Lisanti CJ. MRI: the basics. 2nd ed. Philadelphia: Lippincott Williams \& Wilkins; 2004.

21. Hjort N, Christensen S, Solling C, Ashkanian M, Wu O, Rohl L, et al. Ischemic injury detected by diffusion imaging 11 minutes after stroke. Ann Neurol. 2005 Sep;58(3):462-5.

22. Saur D, Kucinski T, Grzyska U, Eckert B, Eggers C, Niesen W, et al. Sensitivity and interrater agreement of CT and diffusionweighted MR imaging in hyperacute stroke. AJNR Am J Neuroradiol. 2003 May;24(5):878-85.

23. Barber PA, Darby DG, Desmond PM, Gerraty RP, Yang Q, Li T, et al. Identification of major ischemic change. Diffusion-weighted imaging versus computed tomography. Stroke. 1999;30(10): 2059-65.

24. Okamoto K, Ito J, Ishikawa K, Sakai K, Tokiguchi S. Diffusionweighted echo-planar MR imaging in differential diagnosis of brain tumors and tumor-like conditions. Eur Radiol. 2000;10(8): 1342-50.

25. Reddy JS, Mishra AM, Behari S, Husain M, Gupta V, Rastogi M, et al. The role of diffusion-weighted imaging in the differential diagnosis of intracranial cystic mass lesions: a report of 147 lesions. Surg Neurol. 2006 Sep;66(3):246-50; discussion 50-1.

26. Kuker W, Ruff J, Gaertner S, Mehnert F, Mader I, Nagele T. Modern MRI tools for the characterization of acute demyelinating lesions: value of chemical shift and diffusion-weighted imaging. Neuroradiology. 2004 Jun;46(6):421-6.

27. Kono K, Inoue Y, Nakayama K, Shakudo M, Morino M, Ohata K, et al. The role of diffusion-weighted imaging in patients with brain tumors. AJNR Am J Neuroradiol. 2001 Jun-Jul;22(6): 1081-8.

28. Desmond PM, Lovell AC, Rawlinson AA, Parsons MW, Barber PA, Yang Q, et al. The value of apparent diffusion coefficient maps in early cerebral ischemia. AJNR Am J Neuroradiol. 2001 Aug; 22(7):1260-7.

29. Ulug AM, Beauchamp N, Bryan RN, van Zijl PC. Absolute quantitation of diffusion constants in human stroke. Stroke. 1997;28:483-90.

30. Kidwell CS, Saver JL, Mattiello J, Starkman S, Vinuela F, Duckwiler G, et al. Thrombolytic reversal of acute human cerebral ischemic injury shown by diffusion/perfusion magnetic resonance imaging. Ann Neurol. 2000;47(4):462-9.

31. Oppenheim C, Grandin C, Samson Y, Smith A, Duprez T, Marsault $\mathrm{C}$, et al. Is there an apparent diffusion coefficient threshold in predicting tissue viability in hyperacute stroke? Stroke. 2001 Nov;32(11):2486-91.

32. Loh PS, Butcher K, Parsons M, Desmond P, Tress B, Davis S. ADC thresholds do not predict the response to thrombolysis. Stroke. 2005;Dec;36(12):2626-31.

33. Hayman L, Taber K, Ford J, Bryan R. Mechanisms of MR signal alteration by acute intracerebral blood: old concepts and new theories. AJNR Am J Neuroradiol. 1991;12 (5):899-907. 
34. Zamani AA. Imaging of intracranial hemorrhage. In: Rumbaugh CL, Wang A, Tsai FY, editors. Cerebrovascular disease imaging and interventional treatment options. New York: Igaku-Shoin; 1995. p. 232-47

35. Linfante I, Llinas RH, Caplan LR, Warach S. MRI features of intracerebral hemorrhage within 2 hours from symptom onset. Stroke. 1999;30(11):2263-7.

36. Butcher KS, Baird T, MacGregor L, Desmond P, Tress B, Davis S. Perihematomal edema in primary intracerebral hemorrhage is plasma derived. Stroke. 2004;35(8):1879-85.

37. Patel MR, Edelman RR, Warach S. Detection of Hyperacute Primary Intraparenchymal Hemorrhage by Magnetic Resonance Imaging. Stroke. 1996;27(12):2321-4.

38. Lin DD, Filippi CG, Steever AB, Zimmerman RD. Detection of intracranial hemorrhage: comparison between gradient-echo images and $b(0)$ images obtained from diffusion-weighted echoplanar sequences. AJNR Am J Neuroradiol. 2001 Aug;22(7): 1275-81.

39. Hardy PA, Kucharczyk W, Henkelman RM. Cause of signal loss in MR images of old hemorrhagic lesions. Radiology. 1990 Feb; 174(2):549-55.

40. Patel R, Edelman R, Warach S. Detection of hyperacute primary intraparenchymal hemorrhge by magnetic resonance imaging. Stroke. 1996;27:2321-4.

41. Kidwell CS, Chalela JA, Saver JL, Starkman S, Hill MD, Demchuk AM, et al. Comparison of MRI and CT for detection of acute intracerebral hemorrhage. JAMA. 2004 Oct;292(15):1823-30.

42. Greenberg S, Finklestein S, Schaefer P. Petechial hemorrhages accompanying lobar hemorrhage: detection by gradient-echo MRI. Neurology. 1996;46(6):1751-4.

43. Fazekas F, Kleinert R, Roob G, Kleinert G, Kapeller P, Schmidt R, et al. Histopathologic analysis of foci of signal loss on gradientecho T2*-weighted MR images in patients with spontaneous intracerebral hemorrhage: evidence of microangiopathy-related microbleeds. AJNR Am J Neuroradiol. 1999;20(4):637-42.

44. Roob G, Lechner A, Schmidt R, Flooh E, Hartung H-P, Fazekas F. Frequency and location of microbleeds in patients with primary intracerebral hemorrhage. Stroke. 2000;31 (11):2665-9.

45. Roob G, Kleinert R, Seifert T, Lechner A, Kapeller P, Kleinert G, et al. [Indications of cerebral micro-hemorrhage in MRI. Comparative histological findings and possible clinical significance]. Nervenarzt. 1999 Dec;70(12):1082-7.

46. Jeerakathil T, Wolf PA, Beiser A, Hald JK, Au R, Kase CS, et al. Cerebral microbleeds: prevalence and associations with cardiovascular risk factors in the Framingham Study. Stroke. 2004 Aug;35(8):1831-5.

47. Roob G, Schmidt R, Kapeller P, Lechner A, Hartung HP, Fazekas F. MRI evidence of past cerebral microbleeds in a healthy elderly population. Neurology. 1999 Mar 23;52(5):991-4.

48. Chalela JA, Kang DW, Warach S. Multiple cerebral microbleeds: MRI marker of a diffuse hemorrhage-prone state. J Neuroimaging. 2004 Jan;14(1):54-7.

49. Kidwell CS, Saver JL, Villablanca JP, Duckwiler G, Fredieu A, Gough K, et al. Magnetic resonance imaging detection of microbleeds before thrombolysis: an emerging application. Stroke. 2002 Jan;33(1):95-8.

50. Nighoghossian N, Hermier M, Adeleine P, Blanc-Lasserre K, Derex $\mathrm{L}$, Honnorat J, et al. Old microbleeds are a potential risk factor for cerebral bleeding after ischemic stroke: a gradient-echo T2*weighted brain MRI study. Stroke. 2002 Mar;33(3):735-42.

51. Kakuda W, Thijs VN, Lansberg MG, Bammer R, Wechsler L, Kemp $\mathrm{S}$, et al. Clinical importance of microbleeds in patients receiving IV thrombolysis. Neurology. 2005 Oct 25;65(8):1175-8.

52. Zimmerman RA. Recent advances in MR imaging: FLAIR imaging. Crit Rev Neurosurg. 1998 May 13;8(3): 188-92.

53. Noguchi K, Ogawa T, Seto H, Inugami A, Hadeishi H, Fujita H, et al. Subacute and chronic subarachnoid hemorrhage: diagnosis with fluid-attenuated inversion-recovery MR imaging. Radiology. 1997 Apr;203(1):257-62

54. Singer M, Atlas S, Drayer B. Subarachnoid space disease: diagnosis with fluid-attenuated inversion- recovery MR imaging and comparison with gadolinium-enhanced spin-echo MR imaging-blinded reader study. Radiology. 1998 August 1, 1998;208(2): 417-22.

55. Ohta T, Kuroiwa T. Timing of CT scanning after SAH. J Neurosurg. 1985 Nov;63(5):817.

56. van Gijn J, van Dongen KJ. The time course of aneurysmal haemorrhage on computed tomograms. Neuroradiology. 1982; 23(3):153-6.

57. Imaizumi T, Chiba M, Honma T, Niwa J. Detection of hemosiderin deposition by $\mathrm{T} 2 *$-weighted MRI after subarachnoid hemorrhage. Stroke. 2003 Jul;34(7):1693-8.

58. Stoner T, Braff S, Khoshyomn S. High signal in subarachnoid spaces on FLAIR MR images in an adult with propofol sedation. Neurology. 2002 Jul 23;59(2):292.

59. Frigon C, Jardine DS, Weinberger E, Heckbert SR, Shaw DW. Fraction of inspired oxygen in relation to cerebrospinal fluid hyperintensity on FLAIR MR imaging of the brain in children and young adults undergoing anesthesia. AJR Am J Roentgenol. 2002 Sep;179(3):791-6.

60. Manawadu D, Butcher K. Evolving hyperdense middle cerebral artery sign. J Neurol Neurosurg Psychiatry. 2008 Oct;79 (10): 1106.

61. Yu D, Schaefer PW, Rordorf G, Gonzalez RG. Magnetic resonance angiography in acute stroke. Semin Roentgenol. 2002 Jul;37(3): 212-8.

62. Sohn CH, Sevick RJ, Frayne R. Contrast-enhanced MR angiography of the intracranial circulation. Magn Reson Imaging Clin N Am. 2003 Nov;11(4):599-614.

63. Marchal G, Michiels J, Bosmans H, Van Hecke P. Contrastenhanced MRA of the brain. J Comput Assist Tomogr. 1992 JanFeb;16(1):25-9.

64. Debrey SM, Yu H, Lynch JK, Lovblad KO, Wright VL, Janket SJ, et al. Diagnostic accuracy of magnetic resonance angiography for internal carotid artery disease: a systematic review and metaanalysis. Stroke. 2008 Aug;39(8):2237-48.

65. Pomerantz SR, Harris GJ, Desai HJ, Lev MH. Computed tomography angiography and computed tomography perfusion in ischemic stroke: a step-by-step approach to image acquisition and three-dimensional postprocessing. Semin Ultrasound CT MR. 2006 Jun;27(3):243-70.

66. Lev MH, Farkas J, Rodriguez VR, Schwamm LH, Hunter GJ, Putman CM, et al. CT angiography in the rapid triage of patients with hyperacute stroke to intraarterial thrombolysis: accuracy in the detection of large vessel thrombus. J Comput Assist Tomogr. 2001 Jul-Aug;25(4):520-8.

67. Nguyen-Huynh MN, Wintermark M, English J, Lam J, Vittinghoff E, Smith WS, et al. How accurate is CT angiography in evaluating intracranial atherosclerotic disease? Stroke. 2008 Apr;39(4):1184-8

68. Yeung R, Ahmad T, Aviv RI, de Tilly LN, Fox AJ, Symons SP. Comparison of CTA to DSA in determining the etiology of spontaneous ICH. Can J Neurol Sci. 2009 Mar;36(2):176-80.

69. Thompson AL, Kosior JC, Gladstone DJ, Hopyan JJ, Symons SP, Romero F, et al. Defining the CT angiography 'spot sign' in primary intracerebral hemorrhage. Can J Neurol Sci. 2009 Jul; 36(4):456-61

70. Mnyusiwalla A, Aviv RI, Symons SP. Radiation dose from multidetector row CT imaging for acute stroke. Neuroradiology. 2009 Jun 9. [Epub ahead of print]

71. Hjort N, Butcher K, Davis S, Kidwell CS, Koroshetz WJ, Rother J, et al. Magnetic resonance imaging criteria for thrombolysis in acute cerebral infarct. Stroke. 2005;36(2):388-97.

72. Ostergaard L, Sorensen AG, Kwong KK, Weisskoff RM, Gyldensted C, Rosen BR. High resolution measurement of cerebral blood flow using intravascular tracer bolus passages. Part II: Experimental comparison and preliminary results. Magn Reson Med. 1996;36(5):726-36.

73. Ostergaard L, Weisskoff RM, Chesler DA, Gyldensted C, Rosen BR. High resolution measurement of cerebral blood flow using intravascular tracer bolus passages. Part I: Mathematical approach and statistical analysis. Magn Reson Med. 1996; 36(5):715-25. 
74. Ostergaard L, Smith DF, Vestergaard-Poulsen P, Hansen SB, Gee $\mathrm{AD}$, Gjedde A, et al. Absolute cerebral blood flow and blood volume measured by magnetic resonance imaging bolus tracking: comparison with positron emission tomography values. J Cereb Blood Flow Metab. 1998 Apr;18(4):425-32.

75. Wintermark M, Maeder P, Thiran JP, Schnyder P, Meuli R. Quantitative assessment of regional cerebral blood flows by perfusion CT studies at low injection rates: a critical review of the underlying theoretical models. Eur Radiol. 2001;11(7): 1220-30.

76. Nabavi DG, Cenic A, Craen RA, Gelb AW, Bennett JD, Kozak R, et al. CT assessment of cerebral perfusion: experimental validation and initial clinical experience. Radiology. 1999 Oct;213(1): 141-9.
77. Wintermark M, Thiran JP, Maeder P, Schnyder P, Meuli R. Simultaneous measurement of regional cerebral blood flow by perfusion CT and stable xenon CT: a validation study. AJNR Am J Neuroradiol. 2001 May;22(5):905-14.

78. Kudo K, Terae S, Katoh C, Oka M, Shiga T, Tamaki N, et al. Quantitative cerebral blood flow measurement with dynamic perfusion CT using the vascular-pixel elimination method: comparison with $\mathrm{H}_{2}(15) \mathrm{O}$ positron emission tomography. AJNR Am J Neuroradiol. 2003 Mar;24(3):419-26. 